\title{
Estado y territorio: política paternalista en una comunidad industrial argentina en la segunda mitad del siglo $\mathrm{XX}$
}

Leticia Muñiz-Terra. Universidad Nacional de La Plata y Consejo Nacional de Investigaciones Científicas y Técnicas, Ensenada, Argentina.

Juliana Frassa. Universidad Nacional Arturo Jauretche y Universidad Nacional de La Plata, Ensenada, Argentina.

RESUMEN | A lo largo del siglo xx los Estados latinoamericanos han intervenido en sus espacios territoriales de disimiles maneras. En este artículo nos concentramos en la república Argentina y nos preguntamos acerca de la posición que ha tenido el Estado nacional, en su carácter de empresario, como configurador de territorios en los últimos cincuenta ańos del siglo xx. En particular nos interesa recuperar y analizar el rol del Estado en tanto creador y gerenciador de empresas públicas radicadas en espacios locales concretos. Para ello presentamos un estudio de las empresas estatales industriales Yacimientos Petrolíferos Fiscales (YPF) y Astillero Río Santiago (ARs) y estudiamos la configuración material y simbólica de la localidad de Ensenada (Provincia de Buenos Aires). A partir de la utilización de una metodología cualitativa, se analizan las estrategias de intervención de las citadas empresas en el marco del paradigma de gestión paternalista de la fuerza de trabajo, la cual tuvo manifestaciones específicas tanto sobre los trabajadores de dichas empresas como sobre la comunidad y el territorio local.

PALABRAS CLAVE | industrialización, desarrollo regional y local, mercado de trabajo.

abstract | During the twentieth century, Latin American and Caribbean States have intervened in their territories in different ways. In this article we focus on Argentina, regarding the position that the national State has held as manager and employer, and in the configuration of territories in the second half of the twentieth century. Moreover, we analyze the role of the State as creator and manager of companies in specific local areas. For this, we studied the role of industrial state-enterprises such as Yacimientos Petroliferos Fiscales (YPF) and Astillero Rio Santiago (ARS) in the material and symbolic configuration of the town of Ensenada (Buenos Aires Province). Through a qualitative methodological approach, we describe the companies strategies developed under the paradigm of industrial paternalism. We found that strategies had specific manifestations both on workers of such companies as well as on the community and local territory.

KEYORDS | industrialization, regional and local development, labor market. 


\section{Introducción}

A lo largo del siglo xx, los Estados latinoamericanos han intervenido en sus espacios territoriales de disímiles maneras. Tanto desde posiciones gubernamentales más intervencionistas como desde perspectivas más liberales, libradas a la suerte del mercado, han contribuido en la configuración de los distintos espacios locales.

Desde la primera posición, el Estado se ha hecho presente a través de la promoción de instituciones educativas, de salud y deportivas, la creación de empresas públicas productoras de bienes y servicios para el mercado local y la supervisión de la explotación de recursos naturales (minería, petróleo, gas), entre otras formas. Las políticas de los gobierno de cuño liberal, en cambio, han dejado en manos del mercado -es decir, de la oferta del sector privado- la provisión de gran parte de estos bienes y servicios. Ahora bien, la aplicación de dichas políticas ha sido particular según el país y el momento histórico al que se haga referencia.

En este artículo nos concentramos en un enclave industrial de la República Argentina y nos preguntamos acerca de la posición que ha tenido el Estado, en su carácter de empresario, como configurador de territorios en los últimos cincuenta años del siglo xx. En particular nos interesa recuperar el rol del Estado en tanto creador y gerenciador de empresas públicas radicadas en espacios locales concretos. Para ello elegimos un estudio de caso particular, donde analizamos el papel desempeñado por las empresas estatales industriales Yacimientos Petrolíferos Fiscales (YPF) y Astillero Río Santiago (ARS) en la configuración material y simbólica de la localidad de Ensenada (Provincia de Buenos Aires), durante la segunda mitad del siglo pasado.

El trabajo se propone identificar y describir las políticas y los mecanismos, tanto formales como informales, que el Estado, a través de sus empresas, puso en práctica en la localidad de Ensenada con el objetivo de construir un mercado de trabajo local previsible y relativamente estable. Concretamente, nos proponemos describir y analizar las políticas de las empresas estatales ARS e YPF en relación con el uso y reproducción de la fuerza de trabajo y las formas materiales en que dichas políticas se expresaron en el territorio de Ensenada.

Asumiendo que el sector público en Argentina cumplió un rol fundamental en la maduración del proceso de industrialización por sustitución de importaciones, ambas empresas constituyen ejemplos paradigmáticos de la política estatal de promoción de sectores considerados estratégicos para el desarrollo industrial, a partir de la intervención directa en el sector productivo.

El desarrollo industrial en Argentina implicó, también, la puesta en práctica de políticas territoriales concretas que fueron estructurando espacialmente las relaciones sociales, específicamente las relaciones laborales, en los diferentes territorios. ${ }^{1}$ Las políticas de intervención empresarial tomaron forma a través de instituciones que estructuraron la vida fabril y extrafabril de los trabajadores en diferentes aspectos, tales como el trabajo, la vivienda, la formación y la recreación.

1 Los estudios sobre esta temática en Argentina se han abocado principalmente a comprender las formas de intervención empresaria en la reproducción de la fuerza de trabajo (Lobato, 2001; Russo, 2006), siendo más escasas las investigaciones específicas sobre esta dimensión en el caso de las empresas estatales (Palermo \& Soul, 2009). 
El análisis en profundidad de este caso puede aportar algunas pistas para comprender el rol del Estado como configurador de territorios tanto en Argentina como en otros países de América Latina que hayan aplicado políticas territoriales de similares características.

En países como Argentina, el actor empresarial ha ocupado un papel relevante en la configuración de los territorios locales, no solo en su dimensión económico-productiva, sino también en lo social, educativo y cultural. En este marco, los aportes de la Geografía Económica, la Sociología del Trabajo y los Estudios Urbanos producidos en las últimas décadas le han otorgado al concepto de lugar una nueva centralidad y revalorización, en tanto espacio donde se crea y expresa la identidad sociolaboral y se pueden construir nuevas formas de relaciones productivas, conservando y potenciando la historia de un territorio (García Jurado, 2004). En este artículo recuperamos esta conceptualización para iluminar la comprensión de la problemática en estudio.

Respecto a la metodología utilizada, se trata de un enfoque netamente cualitativo que, en la reconstrucción de la política empresarial, se ha valido de diversas fuentes, entre las que cabe señalar los documentos internos de la empresa (comunicaciones, circulares, memorias y balances, datos de personal, etcétera) artículos de diarios locales, documentos sindicales y bibliografía específica sobre empresas estatales.

Si bien no se trata de un estudio comparativo, ya que el objeto de análisis lo constituye la localidad de Ensenada (las empresas son las unidades de observación empírica), nos centraremos en los rasgos comunes observados en la política de intervención sobre el territorio local que desarrollaron las empresas seleccionadas.

La exposición argumentativa del texto se estructura en cuatro partes. En la primera se presentan las principales herramientas conceptuales utilizadas en el análisis. En la segunda parte se realiza una breve descripción del derrotero histórico del Estado empresario argentino. En la tercera parte se desarrollan los conceptos de mercado interno de trabajo, paternalismo estatal y comunidad de fábrica, y se señalan las particularidades que los mismos han adquirido en Argentina. En la cuarta parte se presentan los principales rasgos de la localidad de Ensenada y de las empresas ARS e YPF, analizando luego el discurso estatista de ambas firmas, las políticas empresariales de gestión del trabajo y las prácticas territoriales desplegadas por las empresas analizadas.

Finalmente se plantea una reflexión provisoria respecto a la real dimensión del Estado empresario como configurador de territorios, a partir del espacio concreto analizado.

\section{Nuestras lentes teóricas: la noción de territorio}

Una consensuada definición de territorio asocia este concepto a la producción social del espacio, sosteniéndose que es a través de la práctica social de los actores que el territorio se construye diferencialmente. Esta noción, también presente en la concepción de espacio de Santos (1985), ${ }^{2}$ asimila territorio y espacio social recurriendo

2 La noción de espacio desarrollada por Santos (1985) hace referencia a un conjunto de formas representativas de relaciones sociales del pasado y del presente. El espacio es una estructura integrante de la totalidad social y, como tal, toma un carácter subordinante y subordinado, pues 
a la ya clásica definición de Lefebvre (2005): "la práctica espacial, la representación del espacio y los espacios simbólicos contribuyen de diferentes modos a la producción del espacio de acuerdo a sus cualidades y atributos, de acuerdo a la sociedad o al modo de producción en cuestión y de acuerdo al período histórico” (p. 46).

En este sentido y como seńala Manzanal (2007), "es entonces que el 'territorio' aparece asociado con el ejercicio de poder: el territorio sintetiza relaciones de poder espacializadas, relaciones entre capacidades diferenciales para transformar, producir e imponer acciones y voluntades, sea bajo resistencia o no, bajo conflicto o no. Y esto no es más que reconocer que la producción social del espacio es un resultado del ejercicio de relaciones de poder" (p. 27).

Desde esta perspectiva, Lopes de Souza (1995) caracteriza al territorio como "el espacio definido y delimitado por y a partir de relaciones de poder" (p. 78). El territorio es, entonces, un campo de fuerzas, una red de relaciones sociales, que a la par de su complejidad interna, define un límite, una alteridad. En este sentido, partimos de la premisa de reconocer el territorio como ámbito de imbricación de las múltiples expresiones materiales del poder.

La indagación sobre las prácticas específicas que desarrollan los actores sociales para apropiarse y transformar su lugar constituye un camino necesario para explicar la producción del territorio. La construcción de los territorios solo se comprende a partir del estudio de las relaciones de poder existentes entre los actores individuales y colectivos, proceso en el cual ocupan un lugar protagónico las instituciones privadas y gubernamentales. Sin embargo, el estudio de un territorio no se limita al relevamiento de las prácticas materiales en un espacio determinado. Como sostiene Correia de Andrade (1994, p. 214), "la formación de un territorio da a las personas que en él habitan la conciencia de su participación, provocando el sentimiento de la territorialidad que, de forma subjetiva, crea una conciencia de confraternización entre las mismas”. Es así que la idea de territorialidad incluye dos dimensiones: un sentido material, en tanto es "lo que se encuentra en el territorio y está sujeto a gestión”; y una dimensión simbólica, en tanto "proceso subjetivo de concientización de la población de ser parte de un territorio, de integrar el territorio".

En este sentido, acordamos que es clave "identificar explícitamente territorialidad con relaciones de poder en su manifestación más completa y profunda, material y simbólica, sobre el espacio (...). La territorialidad contempla toda la gama de expresiones, actores y vinculaciones presentes en el territorio y en el poder que el mismo expresa" (Manzanal, 2007, p. 31). En tanto asumimos la definición de territorialidad como "relaciones de poder espacialmente delimitadas, operando sobre un substrato referencial” (Manzanal, 2007, p. 31), el análisis nos lleva a contemplar tanto los elementos materiales como simbólicos involucrados en dicho proceso.

Estas dos dimensiones se expresan también en términos de control y conflicto. Como señala Haesbaert (2006), "el territorio envuelve siempre, al mismo tiempo (...), una dimensión simbólica, cultural, a través de una identidad territorial

es al mismo tiempo productor y producto. El autor sostiene que el espacio es función de una sociedad al mismo tiempo que existe en sí mismo, y en este sentido se impone a la sociedad; estructura las relaciones sociales a la vez que es producto de ellas mismas. 
atribuida por los grupos sociales, como forma de 'control simbólico' sobre el espacio donde viven (siendo también por tanto una forma de apropiación), y una dimensión más concreta de carácter político disciplinar [y político-económico deberíamos agregar]: una apropiación y ordenación del espacio como forma de dominio y disciplinamiento de los individuos" (pp. 93-94).

Desde la perspectiva hasta aquí expuesta, nos interesa, entonces, retomar las nociones de producción, relaciones sociales de poder y esfera simbólica presentes en el concepto de territorialidad, para comprender, concretamente, las formas materiales específicas que adoptaron las prácticas empresariales en el territorio de Ensenada.

\section{El Estado empresario en Argentina}

La inexistencia o el insatisfactorio desempeño del sector privado en ámbitos estratégicos ${ }^{3}$ de la economía argentina dieron origen a una importante intervención del Estado en la producción de bienes y servicios específicos. Sumada al objetivo económico, dicha intervención respondió al interés por parte del Estado de introducir criterios de soberanía, equidad y seguridad social en el funcionamiento de la economía nacional. Así, la creación de empresas públicas en Argentina se fundamentó en los objetivos de "favorecer a la economía nacional, proteger la industria local, alcanzar la autosuficiencia en sectores críticos, conservar los recursos naturales, aumentar la productividad de la economía, (...) y aumentar la potencia económica militar de un país en un contexto de conflicto bélico" (Russo, 2010, p. 4).

Como consecuencia de un conjunto de causales históricas, ideológicas, económicas y políticas emergió en la década del veinte del siglo pasado una nueva concepción de la función estatal, asociada fuertemente al proceso de industrialización. En este sentido, varios trabajos analizan las ideas, objetivos y circunstancias que dieron origen al Estado empresario en Argentina, enfatizándose la relevancia que tuvo el sector público en la maduración del proceso de industrialización por sustitución de importaciones (Schvarzer, 1979).

La creciente participación del Estado en la economía no fue necesariamente producto de posiciones ideológicas "estatistas" por parte de quienes tomaron las decisiones políticas. Como destacan Belini y Rougier (2008), "las fallas del mercado, la escasa disposición del capital privado a tomar a su cargo actividades riesgosas o de baja rentabilidad, la intención de retirarse de algunas empresas extranjeras, requerimientos estratégicos, situaciones monopólicas y actividades que demandaban inversiones de enorme magnitud" (p. 35), fueron las principales causas de la intervención estatal.

Si bien existen diversas periodizaciones posibles de lo que consideramos la etapa de surgimiento y consolidación del Estado empresario en Argentina, podemos señalar que a pesar de las iniciativas tempranas de la década de 1880 , fue en los años veinte que se realizaron las primeras intervenciones directas en la producción, las cuales se consolidaron fuertemente entre 1945 y 1955 durante los gobiernos peronistas, y comenzaron su declinación hacia fines de la década de los setenta.

3 La adjetivación de "estratégicos" hace referencia a aquellos sectores que tienen influencia directa e indirecta en otros sectores industriales o comerciales de la economía nacional y que proveen de insumos o bienes básicos para el desarrollo otros procesos productivos. 
Como consecuencia de la crisis de 1929 y, luego, con el nuevo escenario internacional planteado por la Segunda Guerra Mundial, la economía nacional presentaba diversas restricciones que promovieron el surgimiento de un proyecto industrializador, motivado, fundamentalmente, por sectores nacionalistas e industrialistas del Ejército. Aunque el objetivo original fue expandir y modernizar la capacidad tecnológica de las Fuerzas Armadas, en los hechos, las políticas emprendidas tuvieron consecuencias sobre la estructura económica nacional. Cabe señalar aquí los primeros emprendimientos productivos de magnitud encarados por el Estado nacional: la empresa Yacimientos Petrolíferos Fiscales (YPF), Sociedad Mixta Siderúrgica Argentina (somisa), Industrias Aeronáuticas y Mecánicas del Estado (IAME), la Dirección General de Fabricaciones Militares, Astilleros y Fábricas Navales del Estado, etcétera.

La intervención del Estado en la producción contó con un activo protagonismo de fracciones industrialistas del Ejército, que tuvieron como principal preocupación el proceso de movilización industrial y, como objetivo, el autoabastecimiento nacional. Buena parte de las empresas públicas argentinas han surgido asociadas al objetivo de defensa erigido como elemento clave en el proceso de industrialización del país. Como señala Russo (2010), "el imperativo de la seguridad se impone en esta etapa por sobre las razones económicas. La función militar de defensa frente al exterior justifica el control por parte del Estado de determinados sectores y empresas relacionados con las industrias militares, con los medios de transporte, la comunicación y los productos estratégicos" (p. 8).

El desarrollo de actividades orientadas a la producción de armamentos y "bienes de defensa", y de recursos estratégicos (como el acero y el petróleo), ligadas a las instituciones militares, tiene sus hitos de origen en la creación de YPF (1922), la Fábrica Militar de Aviones (1927), la Fábrica Militar de Aceros (1935), somisA (1947) y la conformación de la Dirección General de Fábricas Militares (1941), que se convertiría en el órgano central de coordinación de las actividades productivas encaradas por las Fuerzas Armadas. Rápidamente dichas actividades desbordaron los requerimientos de dichas entidades, posicionándose como empresas "madres" de diversos sectores industriales en el país. Así, las industrias petrolífera, petroquímica, siderúrgica, de aviación y naval de Argentina tuvieron en sus orígenes la impronta del sector militar (López, 1988).

Los proyectos de industrialización elaborados en el ámbito castrense contemplaron el desarrollo de diversas ramas de la producción, consideradas fundamentales en la provisión de materias primas e insumos para la industria. Muchas de las empresas estatales consideradas estratégicas "fueron expresión de un proceso hegemónico que tuvo en el nacionalismo y el industrialismo dos núcleos de sentido fundamentales (...). La autonomía en la defensa nacional y la independencia económica se constituyeron en 'sentidos nodales' asociados a formas de intervención del Estado en la estructura productiva, caracterizando más de cuatro décadas de un Estado empresario" (Figari, Palermo \& Bustos, 2009, p. 5).

La crisis y reversión del Estado empresario se inició con el gobierno de facto en 1976 y terminó de desarticularse con las reformas neoliberales implementadas en la década de los noventa, particularmente con la política de privatizaciones llevada 
adelante. De ahí en más, la intervención del Estado en el funcionamiento económico fue estructuralmente distinta.

\section{Mercados internos de trabajo, gestión paternalista y "comunidad de fábrica”}

La optimización del uso de la fuerza de trabajo, en tanto objetivo del empresariado, se dirime en la real utilización productiva de la mano de obra, ya que "este comportamiento no puede ser estrictamente predicho, en tanto es una relación social, una relación de poder" (De la Garza, 2006, p. 51). Una herramienta fundamental de la política empresarial fue la configuración de los mercados internos de trabajo, los cuales pueden ser definidos como "una unidad administrativa al interior de la cual la remuneración y asignación del trabajo están determinadas por un conjunto de reglas y procedimientos administrativos" (Doeringer \& Piore, 1971). Las normas institucionales, sustituyendo a la dinámica meramente mercantil, tienen la función de regular el uso de la fuerza de trabajo, haciendo que la mano de obra deje de ser un factor totalmente variable para convertirse en cuasi fijo.

En este sentido, como señala Neffa (2008, p. 150), los mercados internos de trabajo constituyen el "conjunto de relaciones de empleo que se hallan estructuradas mediante reglas (formales e informales) e instituciones que gobiernan la asignación y la formación de precios del trabajo en el seno de las empresas". En la conformación y mantenimiento de estos mercados también intervienen hábitos y costumbres, ya que "cada empresa construye su propia cultura, sus rutinas productivas y elabora códigos de conducta que son internalizados pero que no siempre se explicitan" (Neffa, 2008, p. 152).

La idea misma de mercado interno se asocia a sectores o empresas donde existe una demanda de trabajo estable, que requiere calificaciones específicas (aprendidas en el puesto de trabajo) y promueve cierto grado de compromiso del trabajador con la empresa, todo lo cual favorece la previsibilidad y estabilidad del sistema de empleo interno. Las diversas prerrogativas dispuestas por los empresarios para retener la mano de obra calificada otorgan indirectamente un mayor poder de negociación a los trabajadores y sus sindicatos, quienes, mediante sus reivindicaciones y luchas, también influyen sobre la estructuración del mercado interno, logrando beneficios para su actividad (Craig, 1982).

La noción de mercado interno de trabajo tiene una importante vinculación con los objetivos de las políticas empresariales de tipo paternalistas que se han desarrollado en Argentina desde las primeras décadas del siglo xx. La gestión paternalista del trabajo trata de fijar la vida de los trabajadores en torno a la fábrica y lograr el involucramiento, no solo productivo, sino también ideológico del trabajador con los objetivos de la empresa. De esta manera, el empresario influye en la vida de la familia y de la comunidad donde se establece la fábrica, organizando un complejo aparato de integración y consenso (Russo, 2008).

En términos teóricos, el programa paternalista se centra en la actuación del patrón más allá de la fábrica; es decir, en su intervención en el tiempo de no trabajo y en la puesta a punto de un arsenal específico de técnicas y procedimientos disciplinarios. Entre los principales objetivos que persigue este programa está el reclutamiento de 
la mano de obra, su retención y fijación en un espacio cercano a la fábrica, permitiendo de esta manera la conformación de un mercado interno de trabajo medianamente estable en la firma (Sierra Álvarez, 1990). El paternalismo estructuraba nuevas relaciones sociales tanto al interior como la exterior de la fábrica, penetrando en la vida entera del trabajador, haciendo sentir su presencia "en el terreno de la organización familiar, en los lugares de encuentro y sociabilidad, en las instituciones asistenciales y en toda la actividad social. Los trabajadores industriales y sus familias desarrollaban su vida a la sombra de la fábrica” (Russo, 2008, p. 157).

En Argentina, la gestión paternalista del trabajo fue introducida en las primeras décadas del siglo xx en algunas empresas privadas (Rocchi, 2000), como estrategia de disciplinamiento y desincentivación de la afiliación gremial de los trabajadores. Sin embargo, ante la inexistencia o la insatisfactoria intervención de capitales privados en distintos sectores estratégicos de la economía, y frente a la necesidad de introducir criterios de soberanía, equidad, defensa nacional y seguridad social, hacia la década de los cincuenta el Estado nacional implementó en sus propias empresas un programa de gestión laboral de inspiración paternalista.

Las empresas estatales contribuyeron en gran medida a la configuración socioterritorial de muchas localidades, colaborando en la construcción de infraestructura urbana básica, proveyendo viviendas para los trabajadores de las mismas y propiciando la creación de instituciones educativas y sanitarias para sus empleados, sus familias y la comunidad en general. La política de vivienda es uno de los elementos centrales de un programa paternalista y adquiere las características de un "verdadero anclaje: hacer al obrero poseedor de su habitación es fijarle, es unirle al país donde es propietario. Y no únicamente al país, sino también a la empresa para la que trabajaba: por medio de la propiedad de la vivienda los obreros permanecen más unidos al establecimiento que los emplea" (Sierra Álvarez, 1990, p. 138).

Una de las características de este paternalismo fue la íntima articulación establecida entre la organización del trabajo en la empresa y el espacio extrafabril; es decir, entre los ámbitos de producción material y reproducción de la fuerza de trabajo. La gestión paternalista contribuyó así a que los trabajadores estatales, industriales principalmente pero también del sector servicios, construyeran un imaginario configurado en torno a la empresa estatal que expresaba sentidos compartidos dentro y fuera de las empresas y que, al mismo tiempo apelando a los valores de armonía y fraternidad, velaba las asimetrías propias de la relación capital-trabajo.

Estos imaginarios creados en torno a las empresas, denominados también "comunidad de fábrica” (Palermo \& Soul, 2009), dieron forma, sobre todo en el ámbito extrafabril, a una determinada socialización de los trabajadores que garantizaba una mano de obra estable y disciplinada. La acción de las organizaciones sindicales de las empresas también coadyuvó a reforzar y potenciar el sentido de comunidad en torno a las mismas.

Asimismo, "la apelación a la comunidad fabril involucraba una arquitectura disciplinaria conformada en torno a los sentidos de soberanía y producción de nacionalidad" (Figari, Palermo \& Bustos, 2009, p. 5). Las premisas del Estado paternalista se hicieron eco en las demandas y estrategias de los trabajadores de estas empresas, que internalizaron buena parte de los valores movilizados por la gestión 
empresarial. Como señalan Palermo y Soul (2009) para los casos de somisa e YPF, "la apropiación de las prácticas laborales en clave del 'desarrollo nacional' (...) se inscribía en un proceso de apropiación e incorporación del nacionalismo como valor en las prácticas y estrategias políticas del movimiento obrero. En un sentido amplio, la idea de 'lo nacional' era parte de las coordenadas mediante las cuales las organizaciones sindicales se inscribieron como actores políticos" (p. 8). Así, la apropiación del concepto de nacionalismo por parte del movimiento sindical se asoció con la apelación a la redistribución de la riqueza como deber de Estado.

Las intervenciones por parte de las empresas desbordaron, así, el ámbito de trabajo industrial para expresarse en el territorio local, configurando nuevas relaciones sociales en la comunidad. En nuestro caso, estas prácticas, con sus peculiaridades, se materializaron en la localidad de Ensenada, Provincia de Buenos Aires, a partir de las prácticas desarrolladas por dos grandes empresas estatales: la refinería de ypr y el Astillero Río Santiago.

\section{El territorio de Ensenada y las empresas analizadas: los casos de YPF y Astilleros Río Santiago (ARS)}

La localidad de Ensenada, ubicada al este de la Provincia de Buenos Aires, sobre el litoral sur del Río de La Plata, a $7 \mathrm{Km}$ de la Ciudad de La Plata, fue fundada, junto con su puerto, en el año 1801, debido a la necesidad que tuvo la Corona Española de fortificar las costas del Río de la Plata frente al avance portugués y los contrabandistas ingleses. A pesar de su temprana fundación y del emplazamiento de saladeros, fue recién hacia principios del siglo $\mathrm{xx}$, con la instalación de los frigoríficos en la región (específicamente de los frigoríficos Armour, en 1904, y Swift, en 1915, en la localidad vecina de Berisso), que aumentó el número de habitantes de la ciudad.

El mayor crecimiento socioeconómico y poblacional de la localidad se produjo, sin embargo, en la década de 1920, luego de la construcción de la refinería de YPF. La instalación en los años cincuenta del Astillero Río Santiago (ARS) en la ciudad coadyuvó al crecimiento y desarrollo industrial de la ciudad.

En las décadas posteriores, la industrialización de la región fue completada por el emplazamiento de un complejo petroquímico y siderúrgico ${ }^{4}$ y la apertura de otras empresas de capital privado. ${ }^{5}$ A pesar de ello, fueron las firmas estatales las que dinamizaron la economía y el mercado de trabajo local más fuertemente. La relevancia adquirida por YPF y ARs propició un modelo de integración ligado al trabajo en una empresa nacional y la construcción de una cultura de trabajo peculiar, que dotaba de sentido las acciones de sus empleados.

Ensenada se transformó en una ciudad en la que no era necesario separar los conceptos de comunidad y clase, ya que, como afirma Lobato (2004), se trataba de

4 El sector petroquímico se desarrolló localmente a lo largo de las décadas de los sesenta y setenta con la fundación de Petroquímica Ipako (1962), Propulsora Siderúrgica (1969), Petroquímica General Mosconi (1974) y Copetro s.A. (1978).

5 Entre las empresas más importantes que siguen funcionando en la actualidad, debemos nombrar a Siderar, Polibutenos Argentinos s.A., Aco Sapic, Copetro, Maleic s.A. y Petroken, la mayoría de ellas emplazadas en Ensenada entre fines de los ańos sesenta y medidos de los setenta. 
dos facetas relacionadas por la experiencia de los trabajadores. Fábrica y comunidad fueron entrelazándose así para construir juntas un mundo de significados compartidos, que dio origen a la conformación de una fuerte comunidad e identidad obrera.

\section{FIgURA I | Mapa de Ensenada}

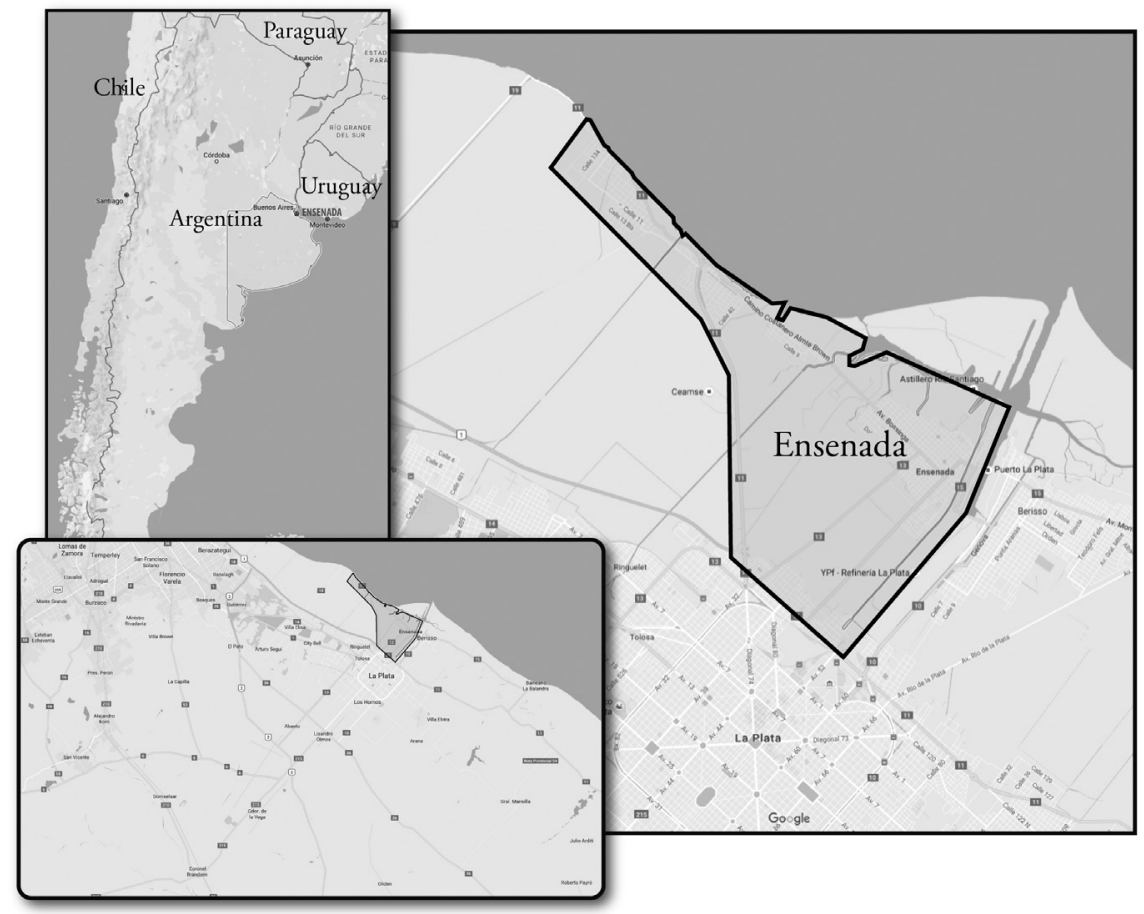

FUENTE ELABORACIÓN PROPIA CON COLABORACIÓN DEL DISEÑADOR GRÁFICO MATÍAS LAQUIDARA

Las dos empresas aquí analizadas pueden ser entendidas como ejemplos paradigmáticos de la voluntad estatal, iniciada a finales de los ańos veinte, de asumir la dirección del desarrollo económico nacional. Si bien ambas firmas presentan diferencias productivas y organizativas insoslayables, es posible observar ciertas similitudes en su concepción como instrumentos promotores del desarrollo industrial y configuradoras del territorio local.

El Astillero Río Santiago (ARS), creado en 1953 bajo la dependencia del Ministerio de Marina, fue ideado como parte de un ambicioso plan estratégico de industrialización pesada. El astillero, especializado en la fabricación y reparación de diversos bienes de capital (tanto construcciones navales como mecánicas), fue creado para satisfacer la creciente demanda interna de la marina mercante, las empresas estatales (la Empresa Líneas Marítimas Argentinas [ELMA], yPf) y la Armada Nacional. El ARs fue, y sigue siendo, el mayor astillero en la Argentina ${ }^{6}$ y, junto con Tandanor,

6 El ARs ocupa el primer lugar en términos de dimensiones edilicias, capacidad instalada y nivel de producción y empleo en la industria naval local. 
las únicas empresas de propiedad estatal existentes en el sector en la actualidad. A lo largo de toda su historia, el ARs ha conservado su carácter de empresa estatal, dependiendo del Gobierno Nacional hasta 1993 y, desde ese entonces, del Gobierno de la Provincia de Buenos Aires.

Por su parte, la empresa Yacimientos Petrolíferos Fiscales (YPF) fue creada por el gobierno nacional en 1922, a raíz del descubrimiento de petróleo crudo en el sur Argentino. Con el correr de los años, esta compañía extendió su actividad productiva a todo el país y se convirtió en la firma nacional explotadora de recursos naturales más relevante de la Nación.

La refinería La Plata, inaugurada en 1925 en la ciudad de Ensenada, ha sido desde siempre la unidad de refinación más importante de la compañía y se ha dedicado desde sus orígenes a la refinación del petróleo crudo (Revista Repsol YPF, 2004). Esta unidad productiva, junto al resto de las refinería y yacimientos petrolíferos de YPF, distribuidos a lo largo del país, tenían como función principal garantizar la satisfacción de las necesidades de petróleo, incrementar la producción de este recurso natural y reducir, en consecuencia, la dependencia del abastecimiento externo. Así, si bien la búsqueda de rentabilidad era un punto que se debía alcanzar para que la compañía pudiera obtener beneficios y mantenerse o crecer en el mercado, este no era, sin embargo, el fin más importante de la empresa. En los ańos noventa la empresa fue sometida a privatización, sufriendo un profundo proceso de achicamiento y reestructuración productiva.

Hasta la última década del siglo $\mathrm{Xx}$, las empresas ARS e YPF desplegaron un conjunto de políticas sociales tendientes a construir un mercado de trabajo local estable y fijo, que favoreció tanto a sus empleados como a los habitantes de la región.

Las prácticas paternalistas de gestión en las empresas analizadas se expresaron en tres niveles diferentes, pero fuertemente imbricados entre sí: el nivel del discurso empresarial, las prácticas internas de gestión de personal y las prácticas territoriales, que se asocian a las políticas extrafabriles, encaradas por las firmas en el espacio local. Para hacer inteligible nuestra argumentación, optamos por describir las prácticas discursivas y materiales llevadas adelante por las empresas analizadas en función de estos tres núcleos temáticos.

\section{El discurso estatista de las firmas}

Los sentidos, valores y premisas que sustentaban el ideario de la empresa estatal ocuparon un rol simbólico central en la conformación de un sentido de comunidad y de involucramiento por parte de sus trabajadores en las empresas.

El carácter estatal de las empresas propició un importante proceso de internalización del discurso industrialista, que colocaba el acento en el control estratégico de los recursos naturales como pilar de la soberanía nacional. La proyección nacional de la firma, la conciencia de trabajar por la "defensa y soberanía" de la Patria y la apelación al "bien común" y la "independencia económica” presentes en el discurso empresarial hicieron mella en la subjetividad de los trabajadores. El desempeńo concreto del trabajo se representaba, en gran medida, vinculado al valor del patriotismo.

Por otro lado, el origen militar de ambas empresas se evidenciaba en la fuerte estructura jerárquica y autoritaria de la organización interna. Las distancias entre 
superiores y supervisados estaban claramente delimitadas y se reforzaban por mecanismos tanto formales (institucionales) como informales (extrafabriles).

En YPF, el discurso estatista fue transmitido por el general Mosconi, director de la empresa desde la creación de la firma en 1922 hasta 1930. Su inspiración militar se tradujo en una concepción de la empresa como un instrumento del patriotismo argentino: cada uno de los trabajadores petroleros era considerado un "soldado civil” (Solberg, 1986, p. 131) que debía bregar por la promoción de los intereses de la patria. La defensa de la empresa se transformaba, de esta manera, en la defensa de la soberanía nacional.

La política sociolaboral instaurada en la empresa petrolera estuvo también fuertemente influenciada por la visión que tenía Mosconi acerca de la organización del mundo del trabajo. El director de ypF era un militar nacionalista que había sido instruido en un ejército argentino fuertemente inspirado en el modelo alemán. $\mathrm{Su}$ mirada respecto del mundo productivo se enmarcaba así dentro del "modelo bismarckiano", es decir, del tipo de relaciones sociolaborales promovidas desde el Estado alemán en el último tercio del siglo xix, que valoraba las intervenciones empresariales en los espacios de subsistencia, en la vivienda obrera, en la asistencia educativa y sanitaria.

El ARs, por su parte, fue creado como parte integrante de la empresa Astilleros y Fábricas Navales del Estado (AFNE) en 1953, en el marco político y simbólico que implicó el Segundo Plan Quinquenal del gobierno de Perón y bajo la dependencia del Ministerio de Marina. En el "Manual doctrinario y práctico" del Plan Quinquenal se establecía como objetivo fundamental, "consolidar la independencia económica para asegurar la justicia social y mantener la soberanía política”.

La creación del ARs respondía, además, a los planes militares del Ministerio de Defensa Nacional, que se planteaba entre sus objetivos: "garantizar el autoabastecimiento de materiales y equipos", "estimular las posibilidades nacionales para el sostén logístico de las Fuerzas Armadas, desarrollando la capacidad de fabricación y producción de armas, municiones y pertrechos bélicos" y "propender a desarrollar la capacidad nacional para el sostén logístico general en la emergencia bélica, especialmente en lo relacionado con las industrias básicas y su fomento".

En concordancia con estos objetivos, la Dirección Empresarial construyó un discurso organizacional orientado a la valoración de la empresa y el trabajo estatal, haciendo hincapié en la importante misión adjudicada al astillero y a sus trabajadores: consolidar la soberanía económica y comercial argentina a través de la construcción de barcos a nivel local. Así, la gestión del astillero promovió entre sus trabajadores un fuerte sentimiento nacionalista y estatista en torno a la función que le cabía a la empresa en el fortalecimiento y la expansión del desarrollo industrial nacional.

\section{Las prácticas de gestión de personal: los mercados internos de trabajo}

Tanto el ARs como ypF desarrollaron mercados internos de trabajo fuertemente regulados, con el objetivo de garantizar la permanencia de la mano de obra a pesar de 
las fluctuaciones de la demanda de producción. Estos mercados hicieron posible la fijación de la mano de obra a la empresa y su regulación en términos de calificación y categorización, lo cual favoreció el desarrollo de carreras profesionales internas. La mayor parte de los empleados presentaba una carrera laboral y profesional ininterrumpida íntimamente ligada a estas empresas. ${ }^{8}$

La estratificación del colectivo de trabajo en ARs se establecía entre el personal de convenio (agremiado a la seccional local ATE Ensenada) y personal jerarquizado (agrupado en la Asociación de Personal Jerárquico y Superior del ARs). El personal de YPF se encontraba en su totalidad bajo convenio colectivo.

De acuerdo con las normas de estos mercados internos, la distribución de las posiciones en las clasificaciones se establecía según los conocimientos y la experiencia en el trabajo (criterios de reclutamiento y categorización) y el grado de entrenamiento práctico, la antigüedad y la formación técnica (entendidos como criterios de promoción). El ingreso de personal a cada una de las empresas guardaba sus peculiaridades, requisitos y dispositivos propios. En el ARs, por ejemplo, el reclutamiento de la fuerza de trabajo se realizaba mediante dos mecanismos formales: el registro de datos que realizaba la propia empresa y la "bolsa de trabajo" del gremio. Las búsquedas de profesionales y mandos medios, por el contrario, se realizaban principalmente de manera informal, recurriendo a las recomendaciones del propio staff de personal jerarquizado o a los convenios de pasantías con las universidades de la región.

Según se establecía por convenio colectivo de trabajo, ${ }^{9}$ en el ARs los familiares de empleados tenían prioridad en el ingreso a la empresa. De manera informal, también se privilegiaba el ingreso de aquellos trabajadores residentes en la región de Ensenada y Berisso, que representan actualmente más del $90 \%$ de la población fabril. Otro de los grupos prioritarios en el reclutamiento de la fuerza de trabajo lo constituyen los egresados de la Escuela Técnica de la empresa $\left(\right.$ ETARs $^{10}$ ) dado el objetivo de la Dirección de captar mano de obra calificada en los oficios navales y socializada en ciertas rutinas organizacionales que los estudiantes van adquiriendo en los años de formación escolar.

En el caso del ARs, por ejemplo, muchos trabajadores iniciaban sus trayectorias profesionales en la Escuela Técnica de la empresa (ETARS), siendo luego incorporados como personal permanente de la planta. Asimismo, para muchos de los trabajadores del astillero, la empresa fue el primero de sus empleos.

9 El convenio colectivo 91/75 “E” fue firmado en 1975 entre Astilleros y Fábricas Navales del Estado S.A. (AFNE) y la Asociación Trabajadores del Estado (ATE), y actualmente sigue vigente por el principio de ultraactividad.

10 La Escuela Técnica Astillero Río Santiago (ETARs), que fuera la Escuela de Aprendices y Especialidades hasta 1959, nace con el objetivo de enseñar a los peones distintos oficios inherentes al área naval. En 1972, pasa a ser considerada Escuela Técnica Privada de Fábrica Astillero Río Santiago, otorgando a sus egresados el certificado de Auxiliar Técnico. La ETARs presenta características pedagógicas y administrativas que la distinguen claramente de otras escuelas. Su emplazamiento en el corazón de la fábrica, la conformación del plantel docente con ingenieros y técnicos de la propia empresa y la posibilidad de acceder a un puesto de trabajo en ella, hacen que la vinculación entre el ámbito académico y laboral sea estrecha. Actualmente en la ETARs se gradúan cerca de cuarenta técnicos por año. El ingreso de alumnos a la escuela es abierto, aunque tienen prioridad los hijos de los trabajadores del ARs. 
Para ingresar a trabajar en YPF, por su parte, era imprescindible tener un familiar que trabajara en la firma o poseer alguna vinculación con el sindicato. Al igual que en el ARs, esta forma de reclutamiento estaba claramente especificada en el convenio colectivo de trabajo, ${ }^{11}$ en el que se señalaba que "para el ingreso a la empresa tenían prioridad las esposas, hijos y familiares de agentes en actividad, jubilados o fallecidos", siempre que tuvieran "la idoneidad profesional, técnica o de cualquier otro orden requeridas por el cargo o funciones a ocupar". Asimismo se le otorgaba a la Federación supe (Sindicato Unidos Petroleros del Estado) la posibilidad de sugerir el nuevo personal de acuerdo con el listado de aspirantes. La "puerta de entrada" al mercado interno de trabajo estaba así específicamente reglamentada.

Los convenios colectivos de ambas empresas presentaban características fuertemente protectoras que reflejaban los rasgos típicos del régimen de relaciones laborales prevaleciente en las empresas públicas hasta los ańos noventa. ${ }^{12}$

La estabilidad del empleo, dadas las características del proceso productivo y su requerimiento de mano de obra calificada, estaba garantizada por la política empresarial, lo cual derivaba en una escasísima tasa de rotación de personal. Asimismo, las condiciones de trabajo fijadas en el convenio garantizaban la capacitación de los trabajadores por parte de la empresa, la posibilidad de promoción, el aumento de salarios por categorización y antigüedad y la existencia de remuneraciones extra a modo de bonificaciones especiales vinculadas al desempeńo global de la empresa (no del rendimiento individual del trabajador).

La formación específica que brindaba cada empresa a sus trabajadores reforzaba la estructuración del mercado interno en tanto posicionaba a la capacitación y, fundamentalmente, la experiencia en el trabajo, como criterio central para el ascenso laboral. Esto implicaba la posibilidad de promoción desde puestos operativos a puestos más calificados y con mando. Tanto en el ARs como en YPF se podía ascender de personal de convenio al estamento de personal jerárquico; se podía comenzar siendo aprendiz y llegar a ser supervisor. Sin embargo, los cargos de gestión estaban restringidos a profesionales que las empresas contrataban específicamente. En el funcionamiento del mercado interno de trabajo de ambas empresas desempeñaba, asimismo, un rol central las organizaciones sindicales.

La historia de las empresas en la localidad implica un desarrollo paralelo de las asociaciones gremiales de Ensenada. En 1927 se creó la Seccional Ensenada de la Asociación Trabajadores del Estado (ATE) que en sus comienzos, y hasta 1944, cuando se creó el SUPE, albergó a los trabajadores de la destilería de YPF. Por su parte, los trabajadores de la Base Naval Río Santiago también eran afiliados de ATE. Cuando muchos de ellos se incorporaron al Astillero Río Santiago, en 1953, se produjo la incorporación gremial de los trabajadores de esta empresa a la seccional de ATE Ensenada. SUPE y ATE se encargaron de bregar porque se cumplieran los derechos de los

11 No 23 de 1975, firmado entre supe y los directivos de YPF. Estuvo vigente hasta la década del noventa.

12 En términos generales, este modelo se caracterizó por expresar un alto grado de intervención estatal, en su doble rol de empleador y regulador, asumiendo una política de protección laboral y favoreciendo el poder institucional del sindicato reconocido con personería gremial (Senen González, 2000). 
trabajadores establecidos en los respectivos convenios colectivos de trabajo, además de ofrecer una serie de políticas asistenciales a los afiliados y sus familias.

Sumado a las características "objetivas" de la relación laboral en la empresa, consolidadas mediante los mecanismos del mercado interno de trabajo, la presencia de relaciones de parentesco (especialmente la filial), el mantenimiento de tradiciones de transmisión-adquisición de saberes en el desempeńo de las tareas y la perdurabilidad de los trabajos de oficio, configuraron un sistema de relaciones laborales de rasgos muy peculiares al interior de cada una de las firmas. Dicho sistema estructuró, en parte, el proyecto de vida personal y familiar de los trabajadores, quienes esperaban poder hacer carrera en la empresa, jubilarse como trabajadores de las empresas, darles la oportunidad a los hijos de trabajar en ellas, etcétera.

Prácticas territoriales: entre el paternalismo empresarial y la comunidad de fábrica Como hemos señalado, gran parte del proceso de socialización del trabajador se realizaba fuera de la fábrica. Las empresas, aplicando políticas claramente paternalistas, promovieron la creación de diversas instituciones que atendían las necesidades de salud, educación y recreación de los trabajadores, al tiempo que otorgaban diversos beneficios sociales tanto para sus empleados como para el conjunto de la comunidad local. Entre estos beneficios cabe destacar, especialmente, los planes de viviendas encarados por las empresas, que buscaban inmovilizar y disciplinar la mano de obra al mismo tiempo que crear un sentido de comunidad de fábrica en el colectivo de trabajadores.

Las instituciones más relevantes en la localidad de Ensenada promovidas por ARS e YPF fueron los clubes sociales, las viviendas y las escuelas de oficios. Todas ellas era la expresión material más visible de la política paternalista desarrollada por las empresas estatales, que garantizaban una "integración subordinada y un sociabilidad regulada”, enfatizando el carácter normativo y de control de la política empresarial (Palermo \& Soul, 2009).

La instalación de las empresas y la creación de estas instituciones tuvieron consecuencias directas sobre la configuración del territorio regional, más allá de la diferencia en alcance y magnitud según la empresa considerada.

YPF fue ubicada con salida al puerto y entre dos canales, en un predio donde abundaban grandes plantas productivas. En sus alrededores se dispusieron los barrios para los obreros y dentro de la empresa se construyeron viviendas para quienes tenían cargos directivos. Estos "barrios petroleros" pusieron en evidencia el modelo de relaciones jerárquicas desplegado al interior de la empresa. Así, los directivos y los profesionales de la compañía, que eran mayoritariamente ingenieros, solían ser ubicados en complejos habitacionales distintos y distantes espacialmente de los barrios en que se asentaban los obreros.

Mientras estas instalaciones constituían para el trabajador una posibilidad concreta de vivir junto a su familia en un lugar estable y con comodidades, para la firma petrolera implicaba la posibilidad de garantizarse el reclutamiento de la mano de obra indispensable para la producción y una garantía de control del colectivo obrero. La posesión de la vivienda contribuía a mejorar la productividad del trabajador y a aumentar las ganancias de la fábrica. 
Esta política se sustentaba en la particular concepción de la productividad que tenían los directivos militares de la empresa, quienes creían que para que el jefe de familia pudiera "entregarse por completo al trabajo con cerebro, corazón y músculo, debía despreocuparse de las necesidades de su hogar" (Archivo de YPF, 1930, citado en Ciselli, 2007, p. 33); es decir, debía tener garantizada la reproducción familiar. Para que fuera posible esta reproducción era además necesario que la esposa se encargara de los quehaceres domésticos -el mantenimiento del hogar y el cuidado de los hijos-, todo lo cual reforzaba un modelo tradicional de familia con una clara división sexual del trabajo.

Las relaciones de poder se expresaban de esta forma en el territorio local. La empresa tenía capacidad para producir e imponer acciones territorializadas y el trabajador las aceptaba y reforzaba cotidianamente, porque se beneficiaba con ellas, al mismo tiempo que creía en el fuerte compromiso que tenía con la defensa y la soberanía de la patria, concepción que se materializaba en el trabajo diario en la empresa.

El ARs, por su parte, también fue localizado con salida propia al río, dada la necesidad de contar con su propio dique de pruebas y de reparaciones de buques. Originalmente la empresa contaba con unas 229 hectáreas de territorio donde se instalaban los diferentes talleres, edificios administrativos y la usina eléctrica. En 1995, como resultado del traspaso de la compañía al gobierno de la Provincia de Buenos Aires y la aprobación de la instalación de una Zona Franca (de libre comercio) en los terrenos que hasta ese entonces eran propiedad del astillero, las instalaciones fabriles quedaron reducidas a solo 23 hectáreas. ${ }^{13}$

En el caso del ARs existieron, entre fines de los años setenta y mediados de los ochenta, planes de viviendas organizados conjuntamente por la Seccional de ATE Ensenada y las Fuerzas Armadas, que estaba al mando de la empresa. Así se llevó adelante la construcción de un importante barrio de chalets individuales y monoblocks en la localidad de La Plata, lindante con la ciudad de Ensenada, llamado barrio Monasterio, donde se instalaron tanto trabajadores del ARS como miembros de la Marina.

En los años noventa se comenzó a construir un nuevo barrio en Ensenada para los trabajadores del ARs, que, sin embargo, quedó a medio construir por la crisis económica y social que tuvo lugar en Argentina entre los años 2000 y 2001. Solo llegó a completarse una parte de las obras que hoy se denomina barrio Coven, donde habitan varios trabajadores del ARs.

Pero las empresas no solo se ocuparon de "fijar" al trabajador a su territorio, sino que también desplegaron una estrategia de desarrollo urbano y regional, al "subsidiar" al territorio local donde se asentaban, logrando traspasar su función productiva para introducirse profundamente en los espacios de la vida cotidiana de los habitantes de la región, de los trabajadores y sus familias. La gestión paternalista de las empresas propició así la construcción de escuelas primarias en la región, apoyó económicamente la creación de algunos establecimientos sanitarios y auspició

13 Recién en el año 2006, parte de ese territorio (unas 20 hectáreas) fue recuperada y, con ella, algunas áreas importantes para la producción y la comodidad de los trabajadores, tales como talleres, patios de trabajo, vestuarios y comedor. 
actividades recreativas, deportivas y culturales, desarrolladas en los clubes sociales creados por los sindicatos locales SUPE y ATE.

$\mathrm{Al}$ respecto, resulta interesante señalar que estas asociaciones gremiales influyeron también en la construcción del territorio ensenadense, al implementar políticas sociales que contribuyeron a conformar el paisaje industrial y obrero de la ciudad. Entre ellas cabe mencionar la creación, por parte de la filial local de suPE, de la biblioteca pública General Mosconi y de la biblioteca infantil Eva Perón, la construcción de un policlínico y de una proveeduría, la instalación de una guardería para los hijos de los trabajadores, la apertura de una farmacia sindical, del Centro de Jubilados y Pensionados de ypF, y la instalación en Punta Lara (barrio de Ensenada) del camping recreativo para los afiliados.

Entre las prácticas sociales y territoriales que llevó adelante el sindicato ATE en los últimos años, cabe señalar la compra de un terreno en el que se planificó una construcción del Centro de Jubilados y Pensionados de ATE, la inauguración en 2004 de la farmacia sindical, la construcción en 2006 de un salón de actos, consultorios, oficinas y un comedor en el local original del gremio, y la adquisición de una hectárea en la ciudad de Berisso para la instalación de un camping recreativo destinado a los afiliados de la seccional.

Las prácticas territoriales desplegadas en Ensenada por YPF y ARS y las respectivas agrupaciones sindicales de sus trabajadores, nos muestran una profunda articulación entre la producción, las relaciones sociales de poder y la dimensión simbólica, que le otorgan a este territorio rasgos particulares que permiten identificar a la ciudad con el mundo del trabajo industrial.

\section{Reflexiones finales}

A partir de lo expuesto, podemos esbozar algunas reflexiones finales sobre la relación entre empresas estatales y territorio local en el caso analizado.

En la localidad de Ensenada, el Estado ha sido un actor social fundamental en la producción material del territorio, puesto que se ha desempeñado como agente de desarrollo, específicamente a través de las prácticas de sus empresas. En este sentido podemos concluir, junto con Palermo y Soul (2009), que "a través de esas intervenciones, el Estado se incrustó en el territorio, consolidando los sentidos de nacionalismo y desarrollo económico asociados a la empresa pública y a quienes formaban parte de su engranaje" (p. 26).

Los ámbitos de la producción y la reproducción social se imbricaron en torno a un ideario de empresa estatal que fue configurando un territorio en el que se expresaron espacialmente las políticas empresariales de carácter paternalista.

En este sentido, en el caso analizado, podemos identificar una íntima relación entre la construcción de ciudadanía y "ser" trabajador de una empresa estatal. La pertenencia a la empresa otorgaba derechos y beneficios que propiciaban la construcción de una identidad sociolaboral ligada a la ocupación de un puesto de trabajo industrial formal, con el que se aportaba al desarrollo de la Nación.

Las empresas aparecen así como referentes centrales en la construcción de la ciudadanía de sus trabajadores, en tanto sujetos de derechos que se perciben a sí 
mismos como forjadores del desarrollo económico nacional. Esta concepción fue reforzada por las prácticas institucionales extralaborales que situaban a los trabajadores en un entramado material y simbólico particular, el cual fue configurando una idea de ciudadanía en sentido ampliado, es decir, asociada al bienestar económico y social garantizado por el Estado.

Esta práctica territorial se vio acompañada de la consolidación de un ideario local ligado a la empresa estatal como promotora de soberanía e independencia económica, que tuvo su expresión más directa y contundente en el apoyo de la comunidad ensenadense a la resistencia a la privatización de ambas empresas en $1990 .{ }^{14}$

La instalación de YPF y ARS en Ensenada adquirió así una significación especial no solo para sus trabajadores sino también para todos los habitantes de la región, que superó la idea de mero emplazamiento geográfico para transformarse en un territorio en el que se crea y expresa una identidad sociolaboral y comunitaria y donde se construyen relaciones productivas que conservan y potencian la historia del territorio.

\section{Referencias bibliográficas}

Belini, C. \& Rougier, M. (2008). El estado empresario en la industria argentina: conformación y crisis. Buenos Aires: Manantial.

Ciselli, G. (2007). Familia y trabajo femenino en YPF. Revista Todo es Historia, (484) (Edición especial), 41-55.

Correia de Andrade, M. (1994). Territorialidades, desterritorialidades, novas territorialidades: os limites dopoder nacional e do poder local. En M. Santos, M. A de Souza \& M. A Silveira (comps), Territorio, globalizacao e fragmentacao (pp 35-51). São Paulo: Editora Hucitec (Humanismo, Ciências e Tecnologia).

Craig J. C., Rubery, J., Tarling, R. \& Wilkinson, F. (1982). Labour market structure, industrial organisation and low pay. Cambridge, MA: Cambridge University Press.

De la Garza, E. (2006). Notas acerca de la construcción social del mercado de trabajo: crítica de los enfoques económico y sociodemográfico. En T. Páramo (coord.), Nuevas realidades y dilemas teóricos en la Sociología del Trabajo (pp. 43-65). México, D.F.: Plaza y Valdés/ Universidad Autónoma Metropolitana Unidad Iztapalapa (UAMI).

Doeringer, P. \& Piore, M. (1971). Internal labor market and manpower analysis. Lexington, MA: Heath Lexington Books.

Figari, C., Palermo, H. \& Busto C. (2009). Construcción de hegemonía, organización y resistencias, en el proceso de privatización de YPF. En P.Lenguita \& J. Montes Cató (comps.), Resistencias laborales. Experiencias de repolitización del trabajo en Argentina (pp. 207-242). México, D.F.: Insumisos.

14 Dicha manifestación, conocida como el "ensenadazo", implicó la movilización de más de 12.000 trabajadores y ciudadanos de la región de Beriso y Ensenada en contra de los planes de privatización y despidos masivos en las empresas ars, IPAKo, Petroquímica General Mosconi y Propulsora Siderúrgica. Dicho evento constituye una de las manifestaciones más populosas y significativas en la historia reciente del movimiento obrero local, que pudo coordinar un reclamo conjunto intergremial en defensa de las fuentes de trabajo de la región. 
Frassa, J. (2016). Voluntad nacional construyendo para el mar: historia de la producción, el trabajo y la cultura en el Astillero Estatal Río Santiago (1953-2010). En C. Russo (comp.), Estado e industria: la construcción naval en Argentina, Brasil, España y Portugal (pp.65-92). Quilmes: Centro Cultural de la Cooperación Floreal Gorini / Universidad Nacional de Quilmes.

García Jurado, Ó. (2004) Bajo la globalización, la idealización de lo local. Rebelión, http:// www.rebelion.org/noticia.php?id=5649

González Cruz, F. (2004). Lugarización, globalización y gestión local. Polis. Revista Latinoamericana, 7, 1-12 . En https://polis.revues.org/6222

Haesbaert, R. (2006). Territórios alternativos. São Paulo: Contexto.

Lahera Sánchez, A. (1998). Fábrica y comunidad. Transformación del trabajo e interdisciplinariedad en la Ciencias Sociales del Trabajo. Sociología del Trabajo, nueva época, 33, 71-102.

Lefebvre, H. (2005). The production of space. Oxford: Blackwel Publishing..

Lobato, M. (2004). La vida en las fábricas. Trabajo, protesta y politica en una comunidad obrera, Beriso (1904-1970), Buenos Aires: Prometeo.

Lopes de Souza, M. (1995). O territorio: sobre espaço e poder, autonomia e desenvolvimento. En I. De Castro, P. da Costa Gómez \& R. Lobato Correa (comps.), Geografia: conceitos e temas (pp. 77-115). Río de Janeiro: Bertrand Edit.

López, E. (1988). La industria militar argentina. Nueva Sociedad, 97, 168-177. En http://nuso. org/media/articles/downloads/1689_1.pdf

Manzanal. M. (2007). Territorio, poder e instituciones. Una perspectiva crítica sobre la producción del territorio. En M. -Manzanal, M. Arqueros \& B. Nussbaumer (comps.), Territorios en construcción, Actores, tramas y gobiernos, entre la cooperación y el conflicto (pp. 3-38). Buenos Aires: ciccus.

Muñiz Terra, L. (2012). Los (ex) Trabajadores de YPF. Trayectorias laborales a veinte años de la privatización. Buenos Aires: Espacio Editorial.

Muñiz Terra, L., Frassa, J. \& Naclerio, A. (2009). Réponses divergentes des firmes face au contexte de restructuration productive: Une comparaison entre deux firmes publiques argentines. Revue Tiers Monde, (200), 895-916. En http://www.memoria.fahce.unlp. edu.ar/art_revistas/pr.7525/pr.7525.pdf

Neffa J. C. (2008). Las teorías de la segmentación de los mercados de trabajo. En F. EymardDuvernay \& J. C. Neffa, Teorías económicas sobre el mercado de trabajo. Análisis institucionalistas (pp. 139-206). Buenos Aires: Fondo de Cultura Económica.

Palermo, H. \& Soul, J. (2009). Petróleo, acero y nación. Una aproximación antropológica a los procesos sociopolíticos de los colectivos de trabajo YPF y somisa. En A. Schneider (comp.), Trabajadores. Un análisis sobre la clase obrera argentina en la segunda mitad del siglo XX (pp. 129-154). Buenos Aires: Herramienta..

Rocchi, F. (2000). Un largo camino a casa: Empresarios, trabajadores e identidad industrial en la Argentina, 1880-1930. En J. Suriano (comp.), La cuestión social en Argentina, 18701943 (pp. 159-190). Buenos Aires: La Colmena.

Russo, C. (2006). Entreprises et territoire: construction de l'identité industrielle au sud de la région métropolitaine de Buenos Aires. Brasserie Quilmes et Cristallerie Rigolleau. Tesis doctoral no publicada. Universidad Sorbonne Nouvelle, Paris III. 
Russo, C. (2008). Fábrica y localidad. La construcción de la identidad industrial: el caso de la cervecería y maltería Quilmes. Revista H-Industria, 2(2), 1-18. En http://ojs.econ.uba. ar/ojs/index.php/H-ind/article/view/478

Russo, C. (2010). El estado empresario y sus motivaciones. Actas del Segundo Congreso Latinoamericano de Historia Económica / Cuarto Congreso Internacional de la Asociación Mejicana de Historia Económica (CLADHe-II/ AMHE- IV), México 2010, pp. 1-15.

Santos, M. (1985). O espaco e método. Sao Paulo: Nobel.

Santos, M. (1996). De la totalidad al lugar. Barcelona: Oikos-Tau.

Schvarzer, J. (1979). Empresas públicas y desarrollo industrial en Argentina. Economía de América Latina, (3), 45-68.

Senen Gonzalez, C. (2000). Relaciones laborales en empresas de servicios públicos privatizadas en Argentina. Los sectores de telecomunicaciones y agua y saneamiento (1990-1998). Tesis de maestría. Centro de Estudios e Investigaciones Laborales (CEIL), Programa de Investigaciones Económicas sobre Tecnología, Trabajo y Empleo (PIETTE) / Consejo Nacional de Investigaciones Científicas y Técnicas (CONICET)

Sierra Álvarez, J. (1990). El obrero soñado. Ensayo sobre el paternalismo industrial. (Asturias, 1860-1917). Madrid: Siglo XxI.

Solberg, C. (1986). Petróleo y nacionalismo en Argentina. Buenos Aires: Hispanoamérica.

Soul, J. (2010). “Acá lo que cambió todo fue la privatización...”. Aproximación antropológica a las prácticas obreras en los espacios laborales en procesos de privatización y reconversión productiva. Theomai, (22), 42-61.

Useche, O. (2008). Los nuevos sentidos del desarrollo. Bogotá: Ediciones Uniminuto.

\section{Fuentes consultadas}

Estatuto de Astilleros y Fábricas Navales del Estado (AFNE), 1953.

Manual doctrinario y práctico del Segundo Plan Quinquenal. Presidencia de la Nación,. Subsecretaría de Informaciones. Buenos Aires, 1953.

Revista Repsol YPF, 2004. Argentina. 